\title{
PENGARUH KUALITAS PRODUK DAN SENI BARISTA TERHADAP MINAT PEMBELIAN MINUMAN PADA RESTORAN DI STARBUCK RESERVE DEWATA BALI
}

\author{
Anak Agung Ayu Arun Suwi Arianty \\ Institut Pariwisata dan Bisnis Internasional \\ ariantyarun@gmail.com
}

\begin{abstract}
ABSTRAK
Menikmati kopi di café telah menjadi gaya hidup masyarakat masa kini. Starbucks Coffee merupakan salah satu kedai kopi terbesar di dunia dan tersebar luas diberbagai Negara. Selain memiliki kualitas kopi terbaik, kini Starbucks Coffee juga menambahkan fasilitas fasilitas kenyamanan seperti Wi-Fi, dan meningkatkan kualitas pelayanan di setiap kedainya yang ditunjukan bagi para pelanggan. Dalam menghadapi persaingan yang ketat Starbucks Coffee selalu memiliki inovasi - inovasi terbaru untuk minuman dan makanan yang ditawarkan setiap tahunnya. Tujuan dari penelitian ini adalah untuk mengetahui pengaruh kualitas produk, pelayanan dan seni bartender terhadap minat pembelian minuman di Starbucks Reserve Dewata, Bali. Penelitian ini menggunakan data kuantitatif dan sumber data primer. Teknik pengumpulan data yang digunakan dalam penelitian ini adalah kuisioner. Sedangkan teknik analisis menggunakan analis regresi linear berganda. Hasil penelitian menjukan bahwa terdapat Pengaruh signifikan antara Kualitas Produk dan Seni Barista Terhadap Minat Pembelian Minuman. Besarnya koefisien determinasi $\left(\mathrm{R}^{2}\right)$ adalah 0,687 atau sama dengan $68,7 \%$. Angka tersebut mengandung arti variabel kualitas produk (X1) dan seni barista (X2) secara berpengaruh terhadap variabel Minat Pembelian Minuman (Y) adalah sebesar 0,687 atau 68,7\%. Sedangkan sisanya 31,3\% dipengaruhi oleh variabel lain yang tidak penulis teliti.
\end{abstract}

Kata Kunci : Kualitas Produk, Seni Barista, Minat Pembelian

\begin{abstract}
Enjoying coffee in a café has become a lifestyle for today's society. Starbucks Coffee is one of the largest coffee shops in the world and is widely distributed in various countries. In addition to having the best quality coffee, now Starbucks Coffee also adds convenience facilities such as Wi-Fi, and improves the quality of service in each shop that is shown for its customers. In the face of intense competition Starbucks Coffee always has the latest innovations for drinks and food that are offered every year. The purpose of this study was to find out the influence of product quality, service and the art of bartenders on the interest in purchasing beverages at Starbucks Reserve Dewata, Bali. This research uses quantitative data and primary data sources. The data collection techniques used in this study are questionnaires. While the analysis technique uses multiple linear regression analysts. The results showed that there is a significant influence between Product Quality and Barista Art on Beverage Purchasing Interest. The amount of the determinant coefficient (R2) is 0.687 or equal to $68.7 \%$. The figure means product quality variable (X1) and barista art (X2) has an effect on the Beverage Purchase Interest (Y) variable of 0.687
\end{abstract}


or $68.7 \%$. While the remaining $31.3 \%$ were influenced by other variables that the authors did not research.

Keywords: Product Quality, Barista Art, Purchase Interest

\section{PENDAHULUAN}

Pada saat ini usaha yang bergerak dalam bentuk café yang menyediakan kopi berkembang sangat pesat di Bali. Kopi beberapa tahun belakangan ini menjadai sangat marak. Menikmati kopi di café telah menjadi gaya hidup masyarakat masa kini. Menurut Sekjen Asosiasi Pengusaha kafe dan restoran Indonesia (2014)"Industri yang menyediakan makanan dan minuman seperti restoran dan kafe di Indonesia semakin meningkat pesat ia mengatakan bahwa saat ini bisnis kafe dan restoran tumbuh sampai mencapain 15-20\%". Starbucks Coffee adalah salah satu perusahaan waralaba yang bergerak dalam bidang penjualan kopi. Starbucks Coffee menyediakan minuman panas yang berbasis espresso serta makanan ringan yang bernuansa espresso yang memakai konsep third place (tempat ketiga) bagi para konsumen setelah rumah dan tempat aktifitasnya.

Starbucks Coffee merupakan salah satu kedai kopi terbesar di dunia dan tersebar luas diberbagai Negara. Selain memiliki kualitas kopi terbaik, kini Starbucks Coffee juga menambahkan fasilitas - fasilitas kenyamanan seperti Wi$\mathrm{Fi}$, dan meningkatkan kualitas pelayanan di setiap kedainya yang ditunjukan bagi para pelanggan.

Dalam menghadapi persaingan yang ketat Starbucks Coffee selalu memiliki inovasi - inovasi terbaru untuk minuman dan makanan yang ditawarkan setiap tahunnya. Adapun pengertian kualitas produk menurut Kotler \& Amstrong (2012:283), adalah kemampuan suatu produk untuk melaksanakan fungsinya meliputi daya tahan, keandalan, ketepatan, kemudahan dalam operasi dan perbaikan serta atribut lainnya. Untuk mencapai kualitas suatu produk, pihak perusahaan harus mengadakan standar operasional perusahaan.

Starbucks Coffee memiliki minuman andalan di setiap musim yang dikenal sebagai seasonal drinks yaitu minuman yang special yang dijual saat musim tertentu sesuai dengan musim yang sedang berlangsung di Amerika. Starbucks juga memberikan free up size dan buy one get one free di setiap 3 bulan sekali bagi para pemegang kartu kredit BCA dan Starbucks Card. Starbucks juga memberikan promosi lainnya seperti voucher, customer voice, dan MAP voucher serta setiap konsumen membeli tumbler dengan menggunakan Starbucks Card akan mendapatkan free drink. Selain itu juga pihak perusahaan juga memberikan pelayanan prima dengan mengandalakan peran dari para barista. Barista adalah sebutan untuk seseorang yang pekerjaannya membuat dan menyajikan kopi kepada pelanggan. Sebagai seorang barista, seni sangat dibutuhkan di dalam operasional kerjanya, menurut Ki Hajar Dewantara, "seni adalah hasil keindahan sehingga dapat menggerakan perasaan indah orang yang melihatnya, oleh karena itu perbuatan manusia yang dapat mempengaruhi dapat menimbulkan perasaan indah itu seni”. Seni sebagai seorang barista yang dimaksud seperti, pembuatan resep minuman atau meracik minuman coffe, cara penyajian minuman, dan atraksi dalam pembuatan minuman coffe. Pembuatan resep minuman adalah suatu proses kreasi dalam mengolah suatu bahan minuman coffe yang bisa menjadi lebih menarik 
dengan menggunakan standar resep tertentu yang telah ditetapkan dimana takaran dan metodenya harus benar dan tepat, karena berpengaruh terhadap cita rasa minuman coffe dan kepuasan tamu. Tujuan dari pembuatan resep yaitu sebagai daya tarik untuk para tamu agar sering datang berkunjung. Penyajian minuman merupakan tata cara atau proses menyuguhkan minuman yang dalam tampilannya disuguhkan semenarik mungkin agar dapat mengundang minat tamu untuk datang dan menikmatinya, diawali dari display awal, garnish, sampai dengan cara menyajikan di atas meja tamu. Konsep gerai yang baru pun mulai diluncurkan dengan hadirnya Starbucks Reserve Dewata.

Starbucks Reserve Dewata merupakan gerai Starbucks terbesar di Asia Tenggara dengan menggusung konsep Coffee Sanctuary (Cagar Kopi). Gerai yang memiliki konsep terbaru ini memiliki merchandise, minuman dan makanan yang eksklusif untuk memikat para konsumen yang dimana hanya dijual di Starbucks Reserve Dewata. Sesuai dengan data yang penulis peroleh, total penjualan di gerai Starbucks Reserve Dewata pada bulan Januari 2019 sebesar Rp. 2.953.427.688 namun mengalami penurunan di bulan Febuari 2019 sebanyak 5\%. Pada bulan Maret penjualan mengalami peningkatan sebesar $10 \%$ dan mengalami penurunan kembali sebesar $12 \%$ di bulan April (Manajemen Starbucks Coffee Dewata Bali, 2019). Menurut Mulyana (2019) menyatakan bahwa kualitas produk dan pelayanan keduanya berpengaruh signifikan terhadap kepuasan pelanggan dan kepuasan pelanggan sendiri berpengaruh signifikan positif terhadap minat beli ulang. Gunarso (2005) mengartikan bahwa minat adalah sesuatu yang pribadi dan berhubungan dengan sikap, individu yang berminat terhadap suatu obyek akan mempunyai kekuatan atau dorongan untuk melakukan serangkaian tingkah laku untuk mendekati atau mendapatkan objek tersebut. Ratnawati (2002) mengemukakan bahwa minat merupakan suatu kecenderungan untuk bertingkah laku yang berorientasi pada obyek, kegiatan dan pengalaman tertentu, selanjutnya menjelaskan bahwa intensitas kecenderungan yang dimiliki seseorang berbeda dengan yang lainnya, mungkin lebih besar intensitasnya atau lebih kecil tergantung pada masing-masing orangnya. Artinya ketika seseorang menyalurkan keinginan dengan suatu tindakan dan terus dilakukan sehingga membentuk kebiasaan maka dapat dikatakan sebagai terbentuknya minat.

Yang artinya dengan meningkatkan kualitas produk dan pelayanan seharusnya mampu mempengaruhi minat konsumen untuk membeli minuman. Akan tetapi hal ini tidak terjadi di Starvucks Reserve Dewata, pihak perusahaan sudah melakukan berbagai upaya dalam mengembangkan fasilitas dan produksi termasuk pelayanannya tetap saja tidak mempengaruhi tingkat penjualan atau dapat dikatakan tidak mempengaruhi minat konsumen untuk membeli produk dari starbucks. Bahkan peran dari barista tidak begitu mempengaruhi kinerja dari perusahaan dalam meningkatkan penjualan. Oleh kareananya peneliti tertarik untuk meneliti tentang keterkaitan produk, pelayanan dan seni bartender terhadap minat konsumen di Starbucks Reserve Dewata.

Berdasarkan latar belakang yang telah dipaparkan, adapun tujuan dari penelitian ini adalah untuk mengetahui pengaruh kualitas produk, pelayanan dan seni bartender terhadap minat pembelian minuman di Starbucks Reserve Dewata, Bali. 


\section{METODE PENELITIAN}

Penelitian ini dilaksanakan dalam jangka waktu 5 bulan. Pemilihan lokasi didasarkan pada beberapa pertimbangan. Penelitian ini dilakukan di Starbuck Reserve Dewata Bali. Starbuck Reserve Dewata Bali adalah salah satu café di kawasan pengembangan Kawasan pariwisata kuta tepatnya dijalan sunset road yang menjadi favorit banyak pecinta kopi, khususnya kalangan generasi milenial. Populasi dalam penelitian ini adalah generasi milenial yang berkunjung ke Starbuck Reserve Dewata Bali. Dikarenakan jumlah populasi tidak diketahu secara pasti maka untuk mengetahui besarnya sample yang digunakan dalam penelitian ini menggunakan teknik kouta sampling.

Untuk mendapatkan data yang diharapkan, maka metode pengumpulan data yang penulis lakukan menggunakan teknik kuesioner. Kuesioner adalah sejumlah pertanyaan tertulis yang digunakan untuk memperoleh informasi dari responden yang menyangkut hal-hal pribadinya atau hal yang diketahui. Menurut Riduwan (2007:71) kuesioner (angket) adalah daftar pertanyaan yang diberikan kepada orang lain bersedia memberikan respon (responden) sesuai dengan permintaan pengguna. Kuesioner yang digunakan dalam penelitian ini adalah kuesioner terstruktur, dimana pertanyaan yang diajukan kepada responden disertai dengan pilihan jawaban sehingga responden hanya memilih jawaban yang telah tersedia. Skala pengukuran untuk semua indikator pada masing-masing variable menggunakan skala likert dimulai dari sangat tidak setuju (STS) sampai dengan sangat setuju (SS).

Teknik analisis data menggunakan analisis regresi. Analisis regresi adalah prosedur statistik untuk menganalisa hubungan antara variabel dependen dan variabel independen. Jika terdapat dua atau lebih variabel bebas maka menggunakan analis regresi linear berganda. Dengan demikian dapat diketahui sejauh mana hubungan sebab-akibat atau pengaruh antara variabel-variabel tersebut.

\section{HASIL DAN DISKUSI}

Penyebaran kuesioner dilakukan pada Bulan Oktober sampai Desember tahun 2020 terhadap 100 orang tamu di Restoran sebagai responden di penelitian ini. Dari 100 kuesioner hanya 80 kuesioner yang kembali dan selanjutnya hasil dari kuisioner tersebut diolah menggunakan program SPSS. Berdasarkan data kuisioner yang telah d kumpulkan dapat dilihat bahwa responden terbanyak adalah dari lakilaki dengan frekuensi 48 orang dan responden prempuan dengan frekuensi 32 orang. Sedangkan untuk umur responden paling banyak adalah dari umur 19 tahun sebanyak 29 responden, yang kedua adalah umur 18 tahun sebanyak 21 responden dan selanjutnya adalah umur 20 tahun sebanyak 17 responden sisanya umur 17 dan 22 tahun. Dan terakhir berdasarkan pekerjaan responden sebagian besar sebagai pelajar yaitu dengan frekuensi 77 orang dibandingkan dengan profesi lainnya yakni pengajar/dosen sebanyak 2 responden, dan PNS sebanyak 1 responden.

\section{Persepsi Responden}

a. Persepsi responden terhadap Kualitas Produk

Variabel kualitas produk pada peneltian ini diukur dengan 10 item pernyataan. Hasil jawaban dan analisis indeks skor jawaban terhadap variabel kualitas produk disajikan gambar berikut: 


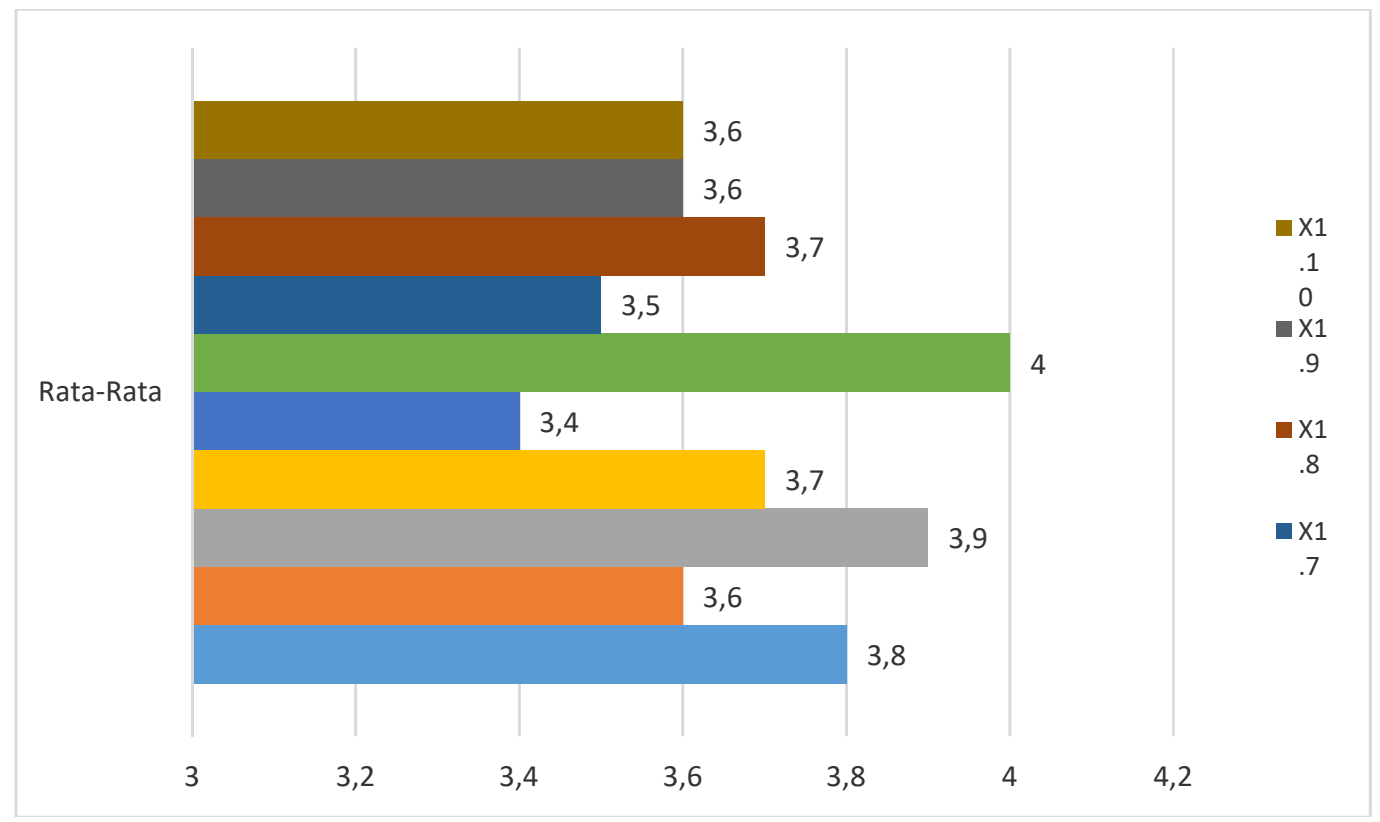

Gambar 1. Indeks Skor Variabel Kualitas Produk

Rata-rata indeks skor jawaban variabel kualitas produk diperoleh sebesar 3,7 berdasarkan kategori indeks skor tersebut rata-rata berada pada tingkat baik. Akan tetapi ada dua pernyataan yang berada pada kategori cukup yakni X1.5 dan X1.7. Untuk pernyatan X1.5 yakni "Ingin membeli minuman di Starbucks Reserve Dewata Bali karena harga minuman yang ditawarkan dengan kualitas seimbang", sedangkan untuk pernyataan X1.7 yakni "Ingin membeli minuman di Starbucks Reserve Dewata Bali karena volume atau porsi minuman yang disajikan sudah sesuai".

b. Persepsi responden terhadap Seni Barista

Variabel seni barista pada penelitian ini diukur dengan 8 butir pernyataan. Hasil jawaban dan analisis indeks skor jawaban terhadap variabel seni barista disajikan dalam tabel sebagai berikut:

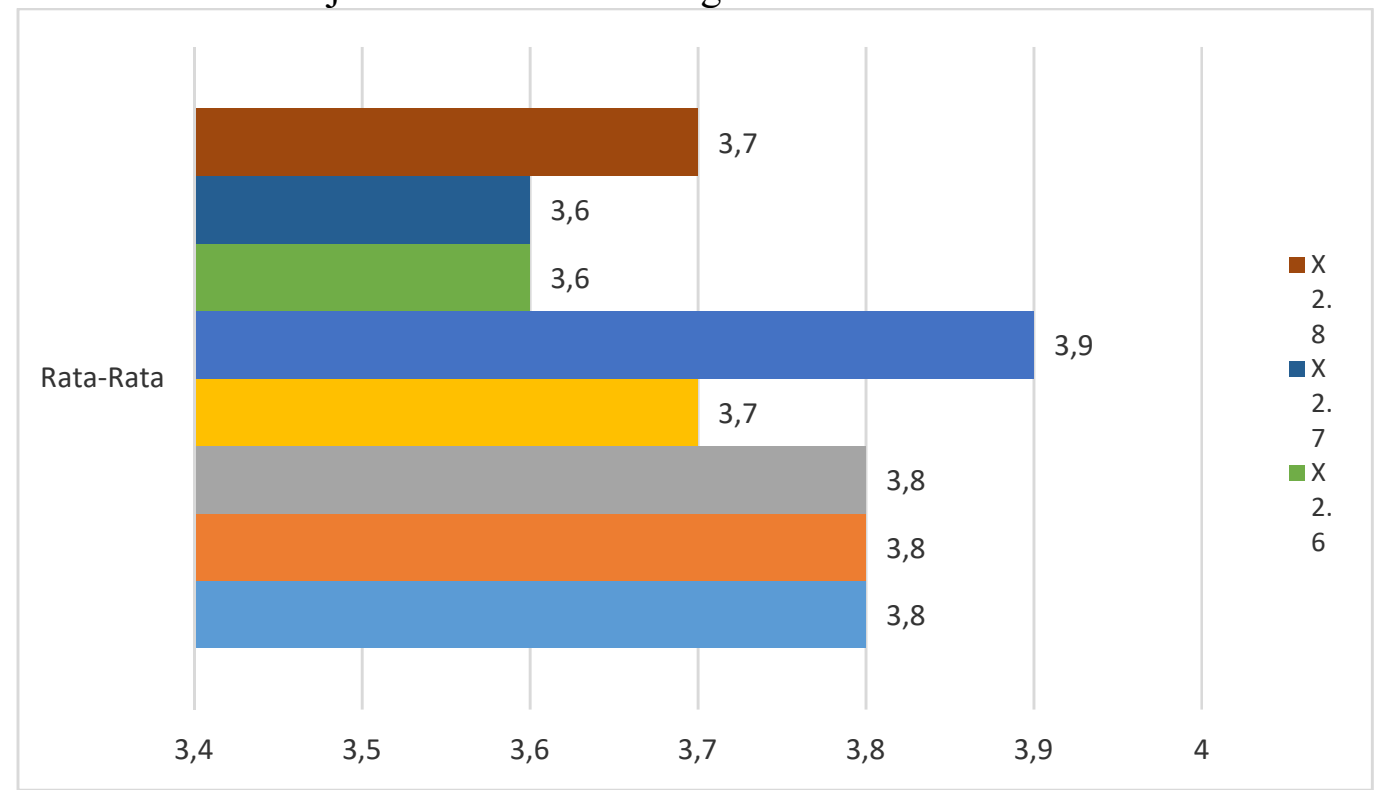

Gambar 2. Indeks Skor Variabel Seni Barista 
Rata-rata indeks skor jawaban variabel seni barista diperoleh sebesar 3,7. Berdasarkan indeks skor, maka rata-rata penilaian responden terhadap variabel seni barista berada pada tingkatan skor baik.

c. Persepsi responden terhadap Minat Pembelian Minuman

Variabel minat pembelian minuman pada penelitian ini diukur 4 buti pernyataan hasil jawaban dan analisis indeks skor jawaban terhadap variabel minat pembelian minuman disajikan dalam tabel sebagai berikut:

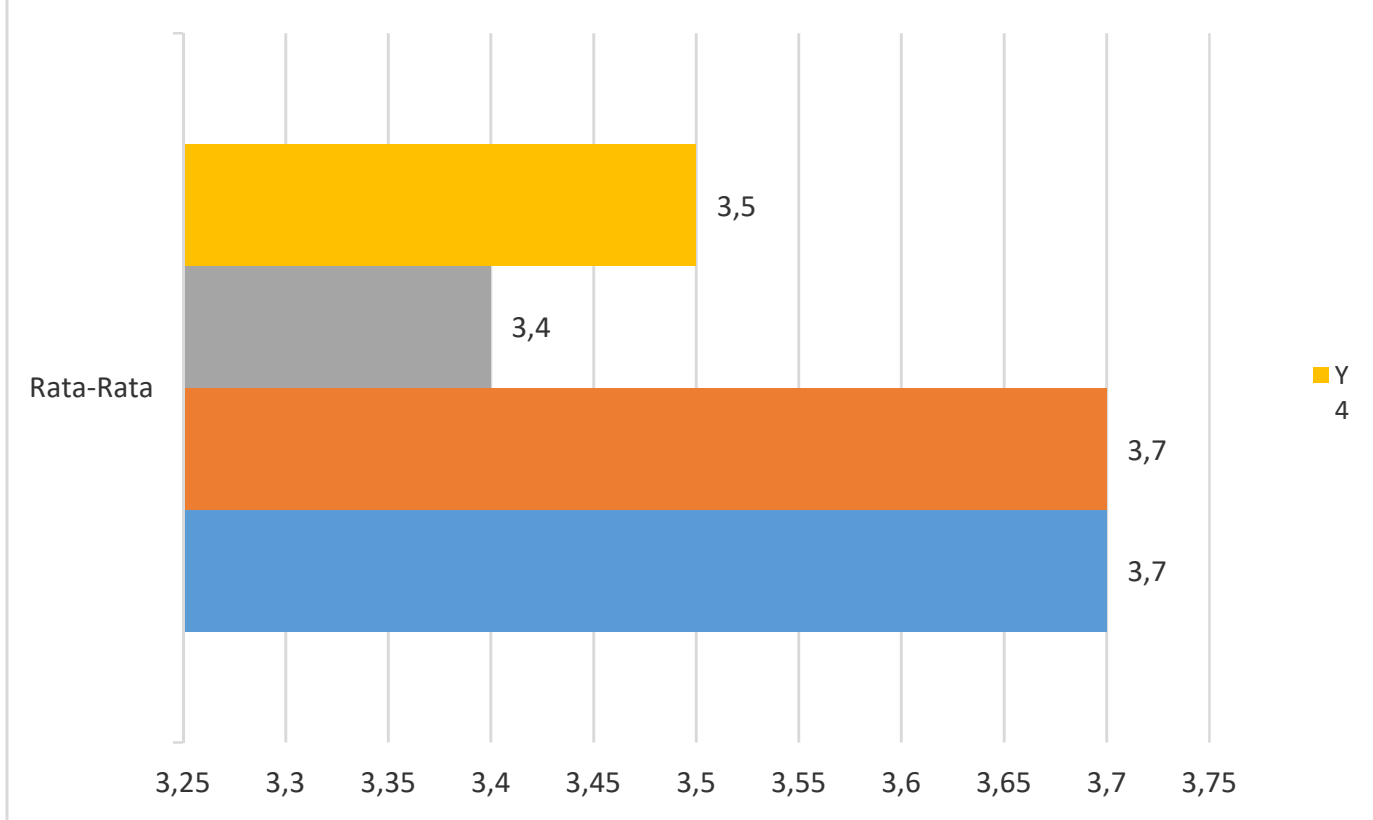

Gambar 3. Indeks Skor Variabel Minat Pembelian Minuman

Rata-rata indeks skor jawaban variabel minat pembelian minuman diperoleh sebesar 3,6. Berdasarkan kategori indeks skor maka rata-rata berada pada tingkat skor baik. Akan tetapi ada dua pernyataan yang berada pada kategori cukup yakni Y3 dan Y4. Untuk pernyataan Y3 adalah "Saya lebih memilih minuman di Starbucks Reserve Dewata Bali dibandingkan dengan restoran lain", sedangkan pernyatan Y4 adalah "Saya selalu mencari informasi mengenai produk minuman di Starbucks Reserve Dewata Bali sebagai acuan dalam menentukan produk minuman yang di inginkan".

\section{Pengaruh Kualitas Produk dan Seni Barista Terhadap Minat Pembelian Minuman}

Analisis yang digunakan pada penelitian ini merupakan analisis regresi linier berganda. Dalam penelitian ini analisis regresi linier berganda untuk mengetahui pengaruh Kualitas Produk, dan Seni Barista terhadap Minat Pembelian Minuman pada Restoran di Bali. Dengan data yang di dapat dari penyebaran kuesioner, maka hasil perhitungan dapat dilihat sebagai berikut: 
Tabel 1. Coefficients Hasil Analisis Regresi Linier Berganda

\begin{tabular}{|l|c|c|l|c|c|}
\hline \multirow{2}{*}{ Model } & \multicolumn{2}{|c|}{$\begin{array}{c}\text { Unstandardized } \\
\text { Coefficients }\end{array}$} & $\begin{array}{c}\text { Standardized } \\
\text { Coefficients }\end{array}$ & \multirow{2}{*}{ t } & \multirow{2}{*}{ Sig. } \\
\cline { 2 - 6 } & $\mathbf{B}$ & $\begin{array}{c}\text { Std. } \\
\text { Error }\end{array}$ & Beta & & \\
\hline (Constant) & 1,024 & 1,035 & & 0,990 & 0,325 \\
\hline X1Total & 0,153 & 0,055 & 0,359 & 2,775 & 0,007 \\
\hline X2Total & 0,255 & 0,066 & 0,497 & 3,847 & 0,000 \\
\hline
\end{tabular}

Sehingga persamaan regresi linier yang terjadi adalah $\mathrm{Y}=1,024+0,153 \mathrm{X} 1$ $+0,255$ X2 atau Minat Pembelian Minuman $=1,024+0,153$ Kualitas Produk + 0,255 Seni Barista. Nilai konstanta sebesar 1,024 hal ini berarti bahwa minat membeli minuman akan sebesar 1,024 jika kualitas produk sama dengan nol dan seni barista bernilai nol. Variabel kualitas produk (X1) mempunyai pengaruh positif terhadap minat membeli minuman dengan koefisien regresi sebesar 0,153 menunjukan bahwa apabila kualitas produk meningkat 1 satuan maka minat pembelian minuman akan meningkat sebesar 0,153 dengan asumsi variabel bebas lain konstan. Sedangkan variabel seni barista (X2) mempunya pengaruh positif terhadap minat membeli minuman dengan koefisien regresi sebesar 0,255 menunjukan bahwa bahwa apabila kualitas produk meningkat 1 satuan maka minat pembelian minuman akan meningkat sebesar 0,255 dengan asumsi variabel bebas lain konstan.

\section{Uji T}

Uji t menunjukkan sebarapa jauh pengaruh satu variabel independen secara individual dalam menerangkan variabel dependen. Pengujian dilakukan dengan menggunakan derajat signifikan $0,05(\alpha=5 \%)$.

Tabel 2. Hasil Uji T

\begin{tabular}{|l|l|l|l|}
\hline Model & t & Sig & Keteragan \\
\hline X1 & 2,775 & 0,007 & Signifikan dan positif \\
\hline X2 & 3,847 & 0,000 & Signifikan dan positif \\
\hline
\end{tabular}

Berdasarkan tabel 4.10 tersebut dapat dilakukan pembandingan nilai Sig. untuk mengetahui pengaruh masing-masing variabel bebas terhadap variabel terikat. Pada variable kualitas produk diperoleh nilai Sig. sebesar 0,007, lebih kecil dari pada 0,05 yang dapat diartikan $\mathrm{H} 0$ ditolak dan $\mathrm{H} 1$ diterima maka secara parsial terdapat pengaruh signifikan antara kualitas produk dengan minat pembelian minuman. Sedangkan variabel seni barista diperoleh Sig. Sebesar 0,000 lebih kecil dari pada 0,05 yang dapat diartikan $\mathrm{H} 0$ ditolak dan $\mathrm{H} 2$ diterima maka secara parsial terdapat pengaruh signifikan antara seni barista dengan minat pembelian minuman.

\section{Uji F}

Uji simultan (Uji F) digunakan untuk menguji secara bersama-sama ada atau tidaknya pengaruh viabel bebas terhadap variabel terikat dapat diketahui dengan menggunakan uji F. Pedoman yang digunakanapabila probabilitas signifikansi $>0.05$, makatidak ada pengaruh signifikan atauHo diterima dan $\mathrm{Ha}$ 
ditolak dan apabila probabilitas signifikansi $<0.05$, makaada pengaruh signifikan atauHoditolak dan Ha diterima.Hasil menunjukkan sebagai tabel berikut:

Tabel 3. Hasil Uji F

\begin{tabular}{|l|l|l|l|l|c|}
\hline \multicolumn{1}{|c|}{ Model } & $\begin{array}{c}\text { Sum of } \\
\text { Squares }\end{array}$ & \multicolumn{1}{c|}{ df } & $\begin{array}{c}\text { Mean } \\
\text { Square }\end{array}$ & \multicolumn{1}{|c|}{ F } & Sig. \\
\hline Regression & 400,095 & 2 & 200,047 & 84,453 & 0,000 \\
\hline Residual & 182,393 & 77 & 2,369 & & \\
\hline Total & 582,488 & 79 & & & \\
\hline
\end{tabular}

Dari hasil output tabel di atas menunukan bahwa hasil signifikasi sebesar $0,000<0,05$. Maka dari analisis di atas dapat disimpulkan bahwa secara bersamasama variabel bebas yang terdiri dari kualitas produk (X1) dan seni barista (X2) berpengaruh signifikan terhadap minat pembelian minuman (Y). Dengan kata lain $\mathrm{H} 0$ ditolak, dan $\mathrm{H} 3$ diterima yang artinya variabel kualitas produk (X1) dan seni barista (X2) secara bersama-sama terpengaruh terhadap minat pembelian minuman.

\section{Koefisien Determinasi $\left(\mathbf{R}^{2}\right)$}

Koefisien determinasi ini dihunakan untuk mengetahui seberapa besar pengaruh variabel-variabel bebas memiliki pengaruh terhada variabel terikatnya. Nilai koefisien determinasi ditentukan dengan nilai $r$ square.

Tabel 4. Hasil Koefisien Determinasi

\begin{tabular}{|l|l|l|}
\hline Model & R & R Square \\
\hline $\mathrm{X} 1, \mathrm{X} 2 \rightarrow \mathrm{Y}$ & 0,829 & 0,687 \\
\hline
\end{tabular}

Predictors: (Constant), X2Total, X1Total

Berdasarkan tabel 4.16 diperoleh hasil analisis korelasi ganda (R) sebesar 0,829 yang menunjukkan besarnya hubungan yang kuat antara kualitas produk dan seni barista terhadap minat pembelian minuman. Pada $R$ Square adalah 0,687 atau $68,7 \%$, sehingga dapat disimpulkan bahwa persentase pengaruh variabel independent terhadap variabel dependent sebesar 0,687 atau $68,7 \%$, sedangkan sisanya $31,3 \%$ dipengaruhi oleh variabel lain yang tidak terdapat dalam penelitian ini.

\section{SIMPULAN}

Berdasarkan hasil pembahasan dengan analisis data yang telah digunakan maka dapat disimpulkan hasil penelitian sebagai berikut:

1. Pengaruh kualitas produk terhadap minat pembelian minuman adalah berpengaruh signifikan dan positif. Kualitas roduk (X1) berpengaruh terhadap minat pembelian minuman $(\mathrm{Y})$, karena nilai sig. lebih kecil daripada 0,05 yang berarti terdapat pengaruh signifikan dan positif. Hal ini berarti kualitas produk ditingkatkan maka akan berpengaruh positif dan signifikan terhadap minat pembelian minuman.

2. Pengaruh seni barista terhadap minat pembelian minuman adalah berpengaruh signifikan dan positif. Seni barista (X2) berpengaruh terhadap minat pembelian minuman (Y), karena nilai sig. Lebih kecil daripada 0,05 yang berarti terdapat pengaruh signifikan dan positif. Hal ini berarti seni barista ditingkatkan maka akan berpengaruh positif dan signifikan terhadap minat pembelian minuman. 
3. Pengaruh Produk dan Seni Barista Terhadap Minat Pembelian Minuman. Besarnya angka koefisien determinasi (R) adalah 0,687 atau sama dengan $68,7 \%$. Angka tersebut mengandung arti variabel kualitas produk (X1) dan seni barista (X2) secara berpengaruh terhadap variabel Minat Pembelian Minuman (Y) adalah sebesar 0,687 atau 68,7\%. Sedangkan sisanya 31,3\% dipengaruhi oleh variabel lain yang tidak penulis teliti.

\section{DAFTAR PUSTAKA}

Gunarso, S. D. (2005). Psikologis Praktis Anak, Remaja danKeluarga. Jakarta: BPK Gunung Mulia Sab'atun.

Kotler, P., \& Amstrong, G. (2012). Prinsip-prinsip Pemasaran (Edisi 13 J). Jakarta: Erlangga.

Manajemen Starbucks Coffee Dewata Bali. (2019). Wawancara dengan Manajemen Starbucks Coffee Dewata Bali.

Mulyana, M. (2019). INISIASI VI: Strategi Penetapan Harga. MATERI TUTORIAL ONLINE EKMA 4216 MANAJEMEN PEMASARAN, 43-51.

Ratnawati. (2002). Mengukur Kepuasan Masyarakatterhadap Pelayanan Pendidikan. Jurnal Pendidikan, 43.

Riduwan. (2007). Skala Pengukuran Variabel-Variabel Penelitian. Bandung: Alfabeta.

Sekjen Asosiasi Pengusaha kafe dan restoran Indonesia. (2014). Omzet Kafe dan Restoran di Indonesia Tumbuh 15\%. Diambil 12 Oktober 2020, dari http://industri.bisnis.com/read/20130411/12/7905/omzet-kafe-dan-restorandi-indonesia-tumbuh-15 